Lượng vi khuẩn ở các răng lộ tủy và không lộ tủy đều giảm có ý nghĩa sau khi điều trị với CHX $2 \%(p<0,001)$ và số vi khuẩn còn lại ở nhóm lộ tủy cao hơn nhóm không lộ tủy có ý nghĩa thống kê $(p<0,05)$. Chứng tỏ, dung dịch $\mathrm{CHX} 2 \%$ đều có hiệu quả diệt khuẩn trên cả hai nhóm tổn thương nhưng hiệu quả diệt khuẩn ở nhóm không lộ tủy lại tốt hơn hẳn, dù lượng vi khuẩn giảm ở nhóm có lộ tủy giảm nhiều hơn so với nhóm không lộ tủy có ý nghĩa thống kê $(p<0,001)$.

Thật vậy, khi ống tủy bị lộ ra môi trường miệng, các vi khuẩn ở miệng đểu có cơ hội xâm nhập vào [2] dẫn đến lượng vi khuẩn ở các răng lộ tủy cao hơn hẳn các răng còn nguyên. Do đó, dù lượng vi khuẩn giảm ở các răng lộ tủy nhiều hơn có ý nghĩa thống kê thì lượng vi khuẩn còn lại sau điều trị vẫn nhiều hơn các răng không lộ tủy đáng kể. Do đó, khi điều trị nội nha nên dùng chất trám tạm để trám kín các ống tủy giữa các lần hẹn và không được mở trống tủy, để tránh sự xâm nhập của các vi sinh vật từ bên ngoài dẫn đến thất bại sau điều trị nội nha.

Hiệu quả sát khuẩn của dung dịch $\mathrm{CHX}$ $2 \%$ trên các răng hoại tử tủy theo các trâm sửa soạn sau cùng. Lượng vi khuẩn ở các nhóm trâm sửa soạn sau cùng đều giảm có ý nghĩa sau khi được điều trị bằng dung dịch $\mathrm{CHX}$ $2 \%(p<0,05)$. Số vi khuẩn còn lại không có khác biệt có ý nghĩa giữa ba nhóm trâm ( $p$ > $0,05)$. Tuy vậy, các ống tủy có kích thước quá lớn vẫn nên sửa soạn thêm với trâm có kích thước lớn hơn để đạt được hiệu quả diệt khuẩn tối đa. Hiện nay, hệ thống trâm Protaper Universal đã bổ sung thêm hai trâm hoàn tất có kích thước lớn hơn là $\mathrm{F} 4$ và $\mathrm{F} 5$ [6], nếu sửa soạn đến F3 mà vẫn chưa thấy chăt ở chóp, vẫn có thể tiếp tục sửa soạn bằng các trâm số lớn hơn này, hoặc chuyển sang kỹ thuật sửa soạn bước lùi với các trâm $\mathrm{K}$-file có kích thước lớn hơn.

\section{KẾT LUÂ̂N}

Dung dịch $\mathrm{CHX} 2 \%$ cho hiệu quả diệt khuẩn tốt trên tất cả các răng hoại tử tủy, kể cả ở nhóm răng trước và răng sau,cũng như nhóm răng hoại tử tủy có lộ tủy và không lộ tủy.

\section{TÀI LIÊU THAM KHẢO}

1. Bộ môn chữa răng - nội nha (2013), "Giáo trình bệnh học răng", Khoa Răng Hàm Mặt, Đại học Y Dược Thành Phố Hồ Chí Minh, tr. 68, 132$155,200-236$.

2. Huy̌̀nh Hữu Thục Hiên (2016), "Vi khuẩn trong nội nha",Cập nhật nha khoa - Tài liệu tham khảo và đào tạo liên tực, Tấp 21 - 2016, Nhà xuất bản Y Học Thành phố Hồ Chí Minh.

3. Ertugrul Ercan, Tuncer $\mathbf{O}^{*}$ zekinci, Fatma Atakul, et al. (2004), "Antibacterial activity of $2 \%$ chlorhexidine gluconate and $5.25 \%$ sodium hypochlorite in infected root canal: in vivo study",] Endod, 30 (2), pp. 84-87.

4. James L. Gutmann, Bing Fan (2016), "Tooth Morphology, Isolation, and Access",Cohen's Pathways of the pulp, Elsevier, 11th Edition, pp. 120-205.

5. Lucio Souza Gonc alves, Renata Costa Val Rodrigues, Carlos Vieira Andrade Junior, et al. (2016), "The Effect of Sodium Hypochlorite and Chlorhexidine as Irrigant Solutions for Root Canal Disinfection: A Systematic Review of Clinical Trials",JOE, 42 (4), pp. 527-532.

6. Markus Haapasalo, Ya Shen (2013), "Evolution of nickel-titanium instruments: from past to future",Endodontic Topics, 29, pp. 3-17.

7. Vianna ME, Horz HP, Gomes BPFA, et al. (2006), "In vivo evaluation of microbial reduction after chemo-mechanical preparation of human root canals containing necrotic pulp tissue", International endodontic journal, 39 (6), pp. 484-492.

8. Peters L. B., Van Winkelhoff A.J., J. F. Buijs, et al. (2002), "Effects of instrumentation, irrigation and dressing with calcium hydroxide on infection in pulpless teeth with periapical bone lesions", International Endodontic Journal, 35, pp. 13-21.

\title{
SO SÁNH Độ BỀN GÃY CỦA COMPOSITE TĂNG CƯờNG SỢI EVERX POSTERIOR VỚI COMPOSITE TRÁM MỘT KHỐI
}

\section{TÓM TẮT}

\footnotetext{
*Đại họ Y Dượ TP HCM

Chịu trách nhiệm chính: Nguyễn Thu Thủy

Email: ntthuy@ump.edu.vn

Ngày nhận bài: 15/2/2021

Ngày phản biện khoa học: 10/3/2021

Ngày duyệt bài: 1/4/2021
}

\section{Nguyễn Thu Thủy*}

Mục tiêu: So sánh độ bền gãy của composite tăng cường sợi everX Posterior và các composite trám một khối SDR, Tetric EvoCeram Bulk Fill, SonicFill. Vật liệu và phương pháp: Nghiên cứu in vitro trên 40 răng cối lớn thứ ba hàm dưới, chia thành 4 nhóm như sau: nhóm 1 (10 răng) trám composite everX posterior, nhóm 2 (10 răng) trám composite SDR, nhóm 3 (10 răng) trám composite SonicFill, nhóm 4 (10 răng) trám composite Tetric EvoCeram Bulk Fill. Kết quả: Độ bền gãy của các composite everX 
Posterior, SDR, SonicFill, Tetric EvoCeram Bulk Fill lần lượt là 2533,5 $\pm 438,4(\mathrm{~N}) ; 2495,7 \pm 747,7(\mathrm{~N})$; $2344,0 \pm 532,6(\mathrm{~N}) ; 2222,4 \pm 387,8(\mathrm{~N})$. Sự khác biệt về độ bền gãy giữa các nhóm thử nghiệm không có ý nghĩa thống kê.Composite tăng cường sợi everX Posterior có tỉ lệ kiểu gãy thuân lợi cao nhất (40\%), kế đến là composite kế đến là SonicFill $(20 \%)$, SDR và Tetric EvoCeram Bulk Fill có tỉ lệ tương đương nhau $(10 \%)$. Sư khác biệt về kiểu gãy giữa các nhóm thử nghiệm không có ý nghĩa thống kê. Kết luận: Độ bền gãy và kiểu gãy giữa composite tăng cường sợi everX Posterior và các composite trám một khối SDR, Tetric EvoCeram Bulk Fill, SonicFill không có khác biệt.

Tư khóa: Fiber composite, bulk composite, fracture toughness

\section{SUMMARY \\ COMPARISON OF FRACTURE TOUGHNESS OF A FIBER REINFORCED COMPOSITE EVERX POSTERIOR AND BULK FILING COMPOSITES}

Objectives: To compare the fracture toughness of a fiber reinforced composite everX posterior and bulk filling compositesSDR, Tetric EvoCeram Bulk Fill, SonicFill. Materials and methods: In vitro study on 40 lower third molars, divided into 4 groups as follows: group 1 (10 teeth) everX posterior composite fillings, group 2 (10 teeth) SDR composite fillings, group 3 (10 teeth) SDR composite fillings and group 4 (10 teeth) Tetric EvoCeram Bulk Fillcomposite fillings. Results: The fracture toughness of everX Posterior, SDR, SonicFill, Tetric EvoCeram Bulk Fill composites is $2533.5 \pm 438.4(\mathrm{~N}), 2495.7 \pm 747.7(\mathrm{~N}), 2344.0 \pm$ $532.6(\mathrm{~N}), 2222.4 \pm 387.8(\mathrm{~N})$. The differences in fracture toughness between 4 groups were not statistically significant. The everX Posterior fiber reinforced composite has the highest favorable fracture pattern rate $(40 \%)$, followed by SonicFill $(20 \%)$, SDR and Tetric EvoCeram Bulk Fill with similar rates $(10 \%)$. The difference in fracture patterns between experimental groups was not statistically significant. Conclusion: Fracture toughness and fracture pattern between fiber reinforced composite everX Posterior and bulk filling composites SDR, Tetric EvoCeram Bulk Fill, SonicFill are no different.

Key words: Fiber composite, bulk composite, fracture toughness.

\section{I. Đă̆T VẤN ĐỀ}

Cùng với sự phát triển của kỹ thuật dán và nhu câu thẩm mỹ gia tăng, composite trở thành vật liệu được lựa chọn cho các phục hồi vùng răng sau. Đặc biệt ở những răng còn sống, chưa điều trị nội nha thì việc mài cùi răng để bọc mão sứ sẽ gây lãng phí thời gian và tiền bạc của người bệnh. Tuy nhiên, nguyên nhân chính gây thất bại trên lâm sàng của miếng trám composite là sâu răng thứ phát và gãy nguyên khối, điều này liên quan đến sự hình thành vi kẽ và sau đó là sự suy thoái của các bề mặt tiếp xúc liên quan đến sự dán phục hồi: ngà răng, chất dán và composite [4]. Sau nhiêu cải tiến đáng kể, phục hôi composite vẫn còn khiếm khuyết về đặc tính cơ học và các vấn đề liên quan đến sự co trùng hợp [66]. Gãy miếng trám, hở bờ, sâu răng tái phát, đau hoăc nhạy cảm sau khi trám răng là những vấn đề thường thấy trên lâm sàng ở những miếng trám composite. Gãy miếng trám thường liên quan đến các đặc tính của vật liệu như khả năng kháng gãy, tính đàn hồi và sự bong dán ở bờ của vật liệu dưới tác động của lực, thường được đánh giá bởi các giá trị tham số như độ bền uốn, độ bền gãy và độ co trùng hợp. Để vượt qua các hạn chế này, các nghiên cứu khác nhau đã được tiến hành nhằm cải tiến các đặc tính của composite bằng cách thay đổi kích thước, phân trăm hạt độn hoặc bởi sư phát triển tính chất hóa hoc của khung nhựa. Gân đây, composite trám một khối được giới thiệu nhằm cải thiện sự biểu hiện của composite phục hồi ở vùng răng sau, được đăt vào xoang với độ dày $4 \mathrm{~mm}$ và được xem là có các đặc tính vật lý và cơ học tốt hơn để chịu được ứng suất nhai cao hơn [1]. Đồng thời giảm thời gian điều trị sẽ làm giảm nguy cơ của môi trường không khí nhiễm khuẩn. Một vài loại composite trám một khối ở dạng lỏng (độ nhớt thấp) như SDR, Filtek Bulk Fill và Venus Bulk Fill, một vài loaị có độ nhớt cao hơn (dạng dẻo) như Tetric EvoCeram Bulk Fill, x-trafil, SonicFill. Trong đó composite everX Posterior với sự tăng cường sợi cũng đã được giới thiệu với mục tiêu gia tăng các đặc tính vật lý và cơ học bằng sự chuyển ứng suất từ khung nhựa sang sợi dựa trên chiêu dài và đường kính sợi [1]. Khảo sát vai trò của sợi thêm vào composite so sánh với các composite trám một khối khác và phạm vi mà sự tăng cường sợi có thể gia tăng các đặc tính cơ học của vật liệu là rất quan trọng [1].

Mục tiêu nghiên cứu: So sánh độ bền gãy của composite tăng cường sợi everX Posterior và các composite trám một khôi SDR, Tetric EvoCeram Bulk Fill, SonicFill.

\section{II. ĐỐl TƯƠNG VÀ PHƯƠNG PHÁP NGHIÊN CỨU}

2.1. Thiết kế nghiên cứu. Nghiên cứu in vitro.

2.2. Đối tượng nghiên cứu. Nghiên cứu được thực hiện trên 40 răng cối lớn thứ ba hàm dưới đã được nhổ vì lý do điêuu trị tai biến mọc răng khôn hoặc chỉnh hình. Các răng được chia thành 4 nhóm sau:

- Nhóm 1: 10 răng (từ 1-10) có miếng trám composite everX Posterior

- Nhóm 2: 10 răng (từ 11-20) có miêng trám composite SDR

- Nhóm 3: 10 răng (từ 21-30) có miêng trám 
composite SonicFill

- Nhóm 4: 10 răng (từ 31-40) có miếng trám composite Tetric EvoCeram Bulk Fill

Tiêu chuẩn chọn mẫu: Thân răng còn nguyên vẹn, không sâu, không có phục hồi hay tổn thương nào trên răng, răng đã đóng chóp, được nhổ cách thời điểm nghiên cứu trong vòng 3 tháng.

Tiêu chuẩn loại trừ: Răng bị nhiễm fluor, răng bị mòn.

\subsection{Phương pháp tiến hành}

Bước 1: Răng được làm sạch bằng máy cạo vôi siêu âm Scaltex 800 (Dentamerica, Taiwan) và các cây cạo vôi tay (Sea Moon, Pakistan), đánh bóng với bột pumice không fluor, ngâmdiệt khuẩn trong dung dịch $\mathrm{NaOCl} 5,25 \%$ trong 5 phút và bảo quản trong nước muối sinh lý $0,9 \%$ cho đến khi sử dụng.

Bước 2: Các răng được thổi khô và được chôn chân răng trong khối nhựa tự cứng UPE ở vị trí dưới đường nối men-xi măng 2 mm.

Bước 3: Sửa soạn xoang trám với chiêu ngoài-trong ở mặt bền bằng $2 / 3$ chiều ngoàitrong của răng, ở eo mặt nhai bằng $1 / 2$ chiều ngoài-trong thân răng, chiều sâu tại eo mặt nhai là $4 \mathrm{~mm}$ tính từ đỉnh múi trong và trên đường nối men-xê măng $1 \mathrm{~mm}$ tại vùng cổ răng của xoang mặt bên. Xoi mòn với acid phosphoric $37 \%$ Rx Etchgel tại men 30 giây, ngà 15 giây, xịt nước rửa xoang 15 giây, thổi khô. Ở nhóm phục hồi với composite everX Posterior và SonicFill bỏ qua giai đoạn này do $\mathrm{G}$-aenial bond và Optibond All-In-One là các hệ thống dán tự xoi mòn.Đặt khuôn trám, thổi khổ răng.

- Nhóm 1 (everX Posterior): Bôi keo dán Gaenial bond, trùng hợp 5 giây. Cho composite Filtek $Z 250$ vào xoang bên, tái tạo $1 \mathrm{~mm}$ thành gần và xa, chiếu đèn 20 giây. Cho composite everX Posterior vào xoang mặt nhai và mặt bên đến vị trí cách mă̆t nhai khoảng $1 \mathrm{~mm}$, chiểu đèn 10 giấy mỗi vị trí. Đặt composite Filtek Z250 vào lớp mặt nhai cuối, điêu khắc và trùng hợp 20 giây. Tháo khuôn trám, tiếp tục chiếu đèn 20 giây.

- Nhóm 2 (XDR): Bôi keo dán Bond Prime and bond NT, trùng hợp 10 giây. Cho composite Filtek Z250 vào xoang bên, tái tạo $1 \mathrm{~mm}$ thành gần và xa, chiếu đèn 20 giây. Cho composite SDR vào xoang mặt nhai và mặt bên đến vị trí cách mặt nhai khoảng $1 \mathrm{~mm}$, nhồi miếng trám, trùng hợp 40 giâymỗi vị trí.Đặt composite Filtek Z250 vào lớp mặt nhai cuối, điêu khắc và trùng hợp 20 giây. Tháo khuôn trám, tiếp tục chiếu đèn 20 giây.

- Nhóm 3 (SonicFill): Bôi keo dán Optibond
All-In-One, trùng hợp 10giây. Đặt đầu con nhộng composite vào phần sâu nhất của xoang. Ấn bàn đạp để kích hoạt tay bơm SonicFill, kéo đâu nhộng di chuyển khắp đáy xoang và nâng cao dần để khối vật liệu đầy đến mặt nhai, điêu khắc tạo hình mặt nhai. Chiếu đèn 20 giây cho mỗi vị trí. Tháo khuôn trám, tiếp tục chiếu đèn 20 giây.

- Nhóm 4 (Tetric EvoCeram Bulk Fill): Bôi keo dán Tetric $\mathrm{N}$ bond, trùng hợp 10 giây. Cho composite Tetric EvoCeram Bulk Fill vào xoang, nhồi và điêu khắc miếng trám, chiếu đèn mỗi vị trí 10 giây. Tháo khuôn trám, tiếp tục chiếu đèn 20 giây.

Hoàn tất và đánh bóng miếng trám với mũi khoan mịn (557) và các đĩa đánh bóng Soflex, trữ trong nước cất ở nhiệt độ phòng trong 24 giờ.

Các mẫu sau đó được chuyển qua Trung Tâm Nghiên Cứu Vật Liệu Polymer- trường đại học Bách Khoa tp HCM để tiến hành đo độ bền gã̃y bằng máy đo lực LLOYD LR30K. Lực và đường cong biến dạng lực được ghi nhận tự động cho mỗi răng.

\section{KẾT QUẢ NGHIÊN CỨU}

3.1. So sánh độ bền gãy giữa các nhóm composite. Độ bền gãy trung bình và độ lệch chuẩn của các nhóm composite everX Posterior, SDR, SonicFill, Tetric EvoCeram Bulk Fill theo thứ tự giảm dần lần lượt là $2533,5 \pm 438,4(\mathrm{~N}), 2495,7$ $\pm 747,7(\mathrm{~N}), 2344,0 \pm 532,6(\mathrm{~N}), 2222,4 \pm 387,8(\mathrm{~N})$.

Sứ dụng phép kiểm Anova 1 yếu tố cho thấy không có sự khác biệt về độ bền gãy giữa các nhóm composite thử nghiệm ( $p>0,05)$ (Bảng 1).

Bảng 1. So sánh độ bền gãy giữa các nhóm thử nghiệm

\begin{tabular}{|c|c|c|c|c|c|}
\hline & $\begin{array}{c}\text { Tổng bình } \\
\text { phương }\end{array}$ & $\begin{array}{c}\text { Độ } \\
\text { tự } \\
\text { do }\end{array}$ & $\begin{array}{c}\text { Trung } \\
\text { bình bình } \\
\text { phương }\end{array}$ & $\mathbf{F}$ & $\mathbf{p}$ \\
\hline $\begin{array}{c}\text { Trong } \\
\text { nhóm }\end{array}$ & 616536,6 & 3 & 205512,2 & 0,7 & 0,5 \\
\hline $\begin{array}{c}\text { Giữa } \\
\text { nhóm }\end{array}$ & $1,067 \mathrm{E} 7$ & 36 & 296390,1 & & \\
\hline Tống & $\mathbf{1 , 1 2 9 E 7}$ & $\mathbf{3 9}$ & & & \\
\hline
\end{tabular}

3.2. Đánh giá kiểu gãy. Kiểu gãy thuận lợi của nhóm composite everX Posterior chiếm tỉ lệ cao nhất $(40 \%)$, kế đến là composite SonicFill $(20 \%)$, composite SDR và composite Tetric EvoCeram Bulk Fill có tỉ lệ tương đương nhau (10\%) (Biểu đồ 1).

Phép kiểm Fisher cho thây không có sự khác biệt về kiểu gãy giữa nhóm composite everX Posterior và composite $\operatorname{SDR}(p=0,303)$, giữa nhóm composite everX Posterior và composite SonicFill ( $p=0,628)$, cũng như giữa nhóm 
composite everX Posterior và composite Tetric EvoCeram Bulk Fill $(p=0,303)$.

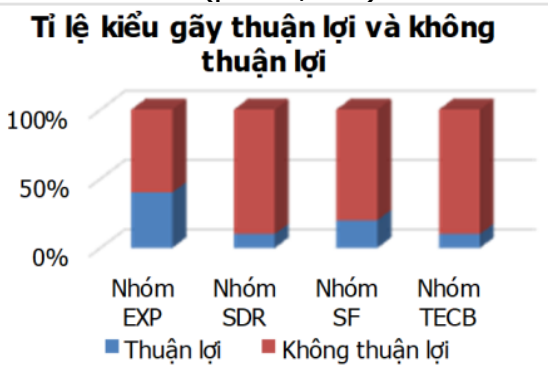

Biểu đồ 1. Ti lệ kiểu gãy của các nhóm nghiên cứu

\section{BÀN LUẬN}

Gần đây, biểu hiện của các vật liệu sinh học hầu hết được đánh giá bằng các thử nghiệm labo. Răng và các phục hồi luôn phải chịu cả lực uốn và lực nén trong quá trình nhai. Hơn nữa, những ứng suất này có thể hiện diện ở mức độ cao hơn trong các vận động cận chức năng như nghiến và cắn chặt hàm. Những nghiên cứu lâm sàng, sau vài năm theo dõi gián tiếp hoăc trực tiếp các phục hồi composite truyền thống ở những vùng chịu lực cao, cho thây gãy phục hồi là kiểu thất bại phổ biến [6]. Độ bền gãy cho thây khả năng kháng lại sự lan truyền vết nứt của các vật liệu giòn, có thể dẫn đến sự gãy dữ dội dưới lực tác dụng. Giá trị độ bền gãy có thể là một dự đoán tốt cho biểu hiện lâm sàng của phục hồi composite [2].

Kết quả nghiên cứu này thể hiện độ bền gãy của composite tăng cường sợi everX Posterior cao hơn so với các composite SDR, SonicFill và Tetric EvoCeram Bulk Fill, tuy nhiên không có sự khác biệt có ý nghĩa thống kê. Composite everX Posterior bao gồm sự kết hợp của khung nhựa, sợi thủy tinh $\mathrm{E}$ không liên tục, và các hạt độn vô cơ. Sự kết hợp này có thể hình thành mạng lưới polymer lan truyền bán phần trong quá trình trùng hợp vật liệu, làm gia tăng đặc tính dán tốt và độ bền của composite [5].

Kết quả này tương đồng với kết quả trong nghiên cứu của Frater $M$ và cs (2014), đánh giá hiệu quả của composite tăng cường sợi so với composite truyền thống (G-aenial posterior) khi phục hồi xoang II MOD trên răng cối với các kỹ thuật trám từng lớp theo phương ngang và phương xiên. Có thể thây rằng răng được phục hồi với composite tăng cường sợi everX Posterior có độ bền gãy và khả năng chịu lực cao hơn, mặc dù sự khác biệt không có ý nghĩa so với composite không có sợi tăng cường, có thể do mô đun đàn hồi thấp của vật liệu, làm gia tăng đặc tính tạo các đường nứt cùn không bén nhọn [3].
Nghiên cứu hiện tại cũng khảo sát kiểu gãy của các mẫu composite. Kiểu gãy thuận lợi khi đường nứt nằm trên vùng nối men-xi măng, nghĩa là răng có thể được tái phục hồi. Trong khi kiểu gãy không thuận lợi khi đường gãy dưới vùng nối men-xi măng, và răng hầu như phải nhổ. Kết quả của thử nghiệm cho thấy phục hồi với composite tăng cường sợi everX Posterior có tỉ lệ gãy thuận lợi cao nhất $(40 \%)$, kế đến là SonicFill (20\%), SDR và Tetric EvoCeram Bulk Fill có tỉ lệ tương đương nhau (10\%). Tuy nhiên không có sự khác biệt giữa các nhóm thư nghiệm. Điều này cũng giống với kiểu gãy trong nghiên cứu của Frater M và cs (2014). Có thể giải thích như sau: khi vết nứt lan truyền từ sợi này sang sợi khác, những vết nứt vi thể và sợi gãy có thể hấp thu năng lượng và do đó làm giảm năng lượng của sự gãy sau cùng. Sợi thêm vào tại giao diện và thay đổi đường lan truyền vết nứt, đặc biệt quan trọng ở những răng có cấu trúc không được nâng đỡ, có thể được sử dụng để tăng cường và ngăn ngừa sự gãy dữ dội của cấu trúc răng [7]. Trong quá trình gãy, các sợi bắt đâu gãy một cách từ từ. Sau khi sự gãy đầu tiên xảy ra, thường do vi nứt của khung nhựa, một phần năng lượng co được giải phóng dưới dạng sóng lan truyền xuyên qua cấu trúc. Khi vết nứt lan truyền từ một sợi sang sợi khác trong composite tăng cường sợi, các sợi hấp thu năng lượng sóng lan truyền. Điều này làm giảm năng lượng của sự gãy sau cùng, làm sự gãy sau cùng ít dữ dội hớn dưới dạng mẻ tại chỗ và hạn chế gãy. Mặt khác, lớp nền composite tăng cường sợi mồ phỏng chức năng nâng đỡ của ngà trong quá trình tác dụng lực và hoạt động như vật liệu thay thế ngà. Cấu trúc ít cứng của composite everX Posterior cho phép vết nút lan xuống xuyên qua cấu trúc composite tạo sự gãy liên kết, không phân tách. Mặc dù kiểu gãy giữa các nhóm không có sự khác biệt, sự tăng cường sợi có ảnh hưởng tích cực lên mức độ gãy do tỉ lệ giữa số lượng miếng trám có thể phục hồi trên không thể phục hồi của everX Posterior cao hơn. Điều này có nghĩa sợi tăng cường có thể chống lại sự gãy không thuận lợi.

\section{KẾT LUẦN}

Độ bền gãy và kiểu gãy giữa composite tăng cường sợi everX Posterior và các composite trám một khối SDR, Tetric EvoCeram Bulk Fill, SonicFill không có khác biệt.

\section{TÀI LIỆU THAM KHẢO}

1. Abouelleil H, Pradelle N, Villat C (2015),

"Comparison of mechanical properties of a new 
fiber reinforced composite and bulk filling composites", Restor Dent Endod 2015,40 (4), pp.262-270.

2. Bonilla E D, Yasharb M, Caputo A A (2003), "Fracture toughness of nine flowable resin composites", The journal of prosthetic dentistry, 89, (3), pp.261-267.

3. Frater $M$, Forster $A$, Kereszturi $M$, Braunitzer G, Nagy K (2014), " In vitro fracture resistance of molar teeth restored with a short fibrereinforced composite material", Journal of dentistry, 42 (9), pp.1143-1150.

4. Fronza $B M$, Rueggeberg FA, Braga RR, Mogilevych B, Soares LES, Martin AA, Ambrosano Glaucia, Giannini M (2015), "Monomer conversion, microhardness, internal marginal adaptation, and shrinkage stress of bulk- fill resin composite", Dental Material, 31 (12), pp. 1542-1551.

5. Garoushi S, Sailynoja E, Vallittu PK, Lassila L (2013), "Physical properties and depth of cure of a new short fiber reinforced composite", Dental Materials, 29 (8), pp.835-841.

6. Garoushi S, Vallittu PK, Lassila LVJ (2011), "Fracture toughness, compressive strength and load-bearing capacity of short glass fiberreinforced composite resin", The Chinese Journal of dental research, 14 (1), pp.15-19.

7. Tezvergil A, Lassila LVj, Vallittu PK (2005), "The shear bond strength of bidirectional and random-oriented fiber-reinforced composite to tooth structure", Journal of Dentistry, 33 (6), pp.509-516.

\section{NGHIÊN CỨU ĐộC TÍNH CẤP VÀ MộT Số TÁC DỤNG SINH HỌC CỦA CAO CHIẾT CÂY MÂM XÔI (RUBUS ALCEAEFOLIUS POIR., HỌ HOA HỒNG ROSACEAE) THU HÁI TẠI THÁI NGUYÊN}

\section{TÓM TẮT}

Mục tiêu: Nghiên cứu đánh giá độc tính cấp, tác dụng chống viêm cấp và tác dụng lợi mật của cao chiết mâm xôi trên thực nghiệm. Đoối tượng và phương pháp: Xác định độc tính cấp đường uống; tác dụng chống viêm cấp trền mô hình gây phù bàn chân chuôt bằng carrageenan và tác dụng lợi mât trên chuột nhẳt trắng theo mô hình của ruddi. Kết quả: Cao chiết mâm xôi có $L D_{50}=12,75 \mathrm{~g} / \mathrm{kg}$. Cao chiết mâm xôi không thể hiện tác dụng chống viêm cấp trên mô hình gây phù bằng carrageenan ở chuột cống. Cao chiết mâm xôi ở cả 2 mức liều $1 \mathrm{~g} / \mathrm{kg}$ và $2 \mathrm{~g} / \mathrm{kg}$ đều thể hiện tác dụng lợi mật với tỷ lệ lượng dịch mật tăng tương ứng $32,79 \%$ và $41,30 \%$. Kết luận: Cao chiết mâm xôi có $\mathrm{LD}_{50} 12,75=\mathrm{g} / \mathrm{kg}$, có tác dụng lợi mật.

Tư khóa: Cao chiết mâm xôi, độc tính cấp, tác dụng lợi mật, tác dụng chống viêm cấp, Thái Nguyên.

\section{SUMMARY}

\section{STUDYING THE ACUTE TOXICITY AND SOME BIO-EFFECTS OF RUBUS ALCEAEFOLIUS POIR. EXTRACT, ROSACE IN THAI NGUYEN}

Objective: To evaluate the acute toxicity, acute anti-inflammatory effect and choleretic effect of Rubus alceaefolius Poir. extract in vivo. Objects and method: Determination of oral tocicity; acute anti-

*Trường Đại học Y Dược Thái Nguyên Chịu trách nhiệm chính: Nguyễn Văn Dũng Email: dung.dhdtn@gmail.com Ngày nhân bài: 17/2/2021 Ngày phản biện khoa học: 14/3/2021 Ngày duyệt bài: 7/4/2021
Nguyễn Văn Dũng*, Trần Ngọc Anh*, Phạm Thị Tuyết Nhung*, Bùi Thị Luyến*

inflammatory effect in model inflammation carrageenan-induced paw edema and choleretic effect in mice following the model of ruddi. Result: The Rubus Alceaefolius Poir. extract has $\mathrm{LD}_{50}=12.75 \mathrm{~g} / \mathrm{kg}$. The Rubus Alceaefolius Poir. extract didn't show acute anti-inflammatory effect in model inflammation carrageenan-induced paw edema in rats. The Rubus Alceaefolius Poir. extract at doses of $1.0 \mathrm{~g}$ and $2.0 \mathrm{~g} / \mathrm{kg}$ body weight significantly increased bile levels by $32.79 \%$ and $41.30 \%$ respectively. Conclusion: The Rubus Alceaefolius Poir. extract has $\mathrm{LD}_{50}=12.75 \mathrm{~g} / \mathrm{kg}$ and choleretic effect.

Keyword: Rubus Alceaefolius Poir. extract, acute toxicity, choleretic effect, acute anti-inflammatory, Thai Nguyen.

\section{I. ĐĂT VẤN ĐỀ}

Cây Mâm xôi (Rubus alceaefolius Poir., họ Hoa Hồng Rosaceae) được người dân sử dụng khá nhiều trong cuộc sống hằng ngày, quả thường được dùng để ăn, làm thuốc chữa đau thận hư, tinh ứ, liêt dương, đái són, hoạt tinh; cành lá già phơi khô, nấu nước uống thay chè giúp dễ tiêu hóa, lợi tiểu, chống viêm. Theo kết quả nghiên cứu của Nguyễn Văn Dũng và cộng sự (2019) cho thấy cao chiết mâm xôi có tác dụng hỗ trợ điều chỉnh rối loạn lipid máu [4], và nghiên cứu của Phạm Hồng Châu (2008) cho thấy cao chiết mâm xôi liều $4 \mathrm{~g}$ dược liêu/ $\mathrm{kg} / \mathrm{ngày}$ x 3 ngày (tương đương $0,4 \mathrm{~g}$ dược liệu/kg người) có tác dụng tăng tiết 44,07\% dịch mật [1], tiếp nối các kết quả nghiên cứu trên, chúng tôi tiến hành đề tài này với mục tiêu: (1) 